\title{
Markov approach to evaluate the availability simulation model for urea decomposition system of a fertilizer plant
}

\author{
Sanjeev Kumar*and Ruchika Singh ${ }^{\#}$ \\ ${ }^{1}$ Mech. Engg. Deptt. YMCA University of Science \& Technology, Faridabad \\ ${ }^{2}$ EN Deptt. Krishna Institute of Engineering \& Technology, Ghaziabad \\ Email: *skumar.ymca@gmail.com,\# ruchika.singh@kiet.edu
}

This paper aims to propose a methodology based on Markov approach to evaluate the availability simulation model for urea decomposition system in a fertilizer plant under realistic working environment. The availability simulation model (Av.) has been developed with the help of mathematical formulation based on Markov BirthDeath process using probabilistic approach. For this purpose, first differential equations have been generated. These equations are then solved using normalizing condition so as to determine the steady state availability of fertilizer system. The results of this paper are therefore, considered to be useful for the availability analysis of a fertilizer plant concerned.

In urea decomposition, oil and oxygen mixed steam are fed to gasifier, allowed to react producing the mixture of $\mathrm{CO}, \mathrm{H}_{2}, \mathrm{~N}_{2}, \mathrm{CH}_{4}, \mathrm{SO}_{2}, \mathrm{H}_{2} \mathrm{~S}$ called raw gases at $55 \mathrm{Kg} / \mathrm{cm}^{2}$ pressure and $350{ }^{\circ} \mathrm{C}$ temperature. High temperature and pressure of mixture is reduced to $200{ }^{\circ} \mathrm{C}$ and $50.5 \mathrm{Kg} / \mathrm{cm}^{2}$ by passing through the waste heat boiler and economizers. Further carbon removal is done by using carbon scrubber [1]

The urea decomposition system comprises of six subsystems arranged in series: Subsystem (B1) reboiler, subsystem (B2) falling film heater, subsystem (B3) highpressure absorber, subsystem (B4) low-pressure absorber, subsystem (B5) gas separator and subsystem (B6) two-heat exchanger. The transition diagram [3] of urea decomposition system shows the various possible states, the system can acquire. Based on the transition diagram, a performance evaluating system has been developed. The failures and repairs for this purpose have been modelled as birth and death process.

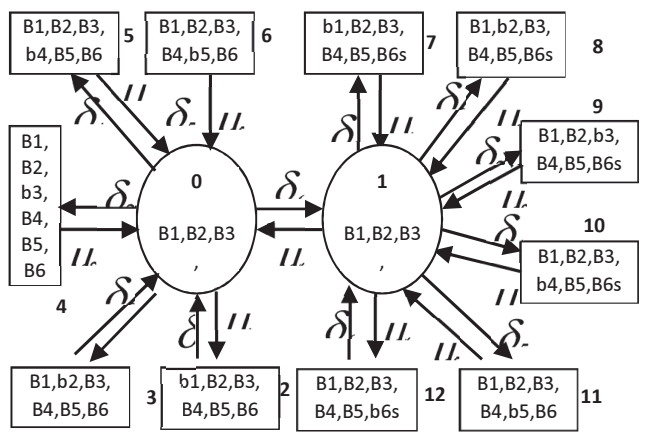

Figure 1: Markov diagram of urea decomposition

\section{Availability Model}

The system starts from a particular state at time't' and reaches to another state (failed) or remain in the same state (operative) during the time interval $\Delta \mathrm{t}$, this transition depends upon the preceding state of the system. Stochastic system defines the condition at any instant of time and the information is useful in analyzing the current state and in predicting of failure state of the system. Modeling is done using simple probabilistic considerations and differential equations are developed using Markov birth-death process [2]

\section{Steady State Availability}

Now, the steady state availability is obtained as sum of all working and reduced capacity state probabilities, [2] Av. $=\sum_{i=0}^{1} P i=\mathrm{P}_{0}+\mathrm{P}_{1}=\left\{1+\delta_{6} / \mu_{6}\right\} / N$, where $\mathrm{N}=\left(1+\delta_{1} / \mu_{1}+\delta_{2} / \mu_{2}+\delta_{3} / \mu_{3}+\delta_{4} / \mu_{4}+\delta_{5} / \mu_{5}+\delta_{6} / \mu_{6}\right)\left(1+\delta_{6} / \mu_{6}\right)$ Therefore, Availability of the system (Av.) represents the model for availability analysis of urea decomposition system

\section{Conclusions}

It can be concluded that this availability model is effectively used for the analysis of availability and hence the evaluation of performance of various sub-systems of urea decomposition system of a fertilizer plant. It also shows the relationship among various failure and repair rates $\left(\alpha_{i}, \beta_{i}\right)$ for each subsystem, that is, urea decomposition system of a fertilizer plant. The findings of this paper are discussed with the concerned fertilizer plant management. Such results are found highly beneficial to the plant management for the analysis of availability and hence to decide about the repair priorities of various systems of urea decomposition system in a fertilizer plant.

\begin{tabular}{|l|l|l|l|}
\hline $\begin{array}{l}\text { S. } \\
\text { No }\end{array}$ & $\begin{array}{l}\text { Failure Rates } \\
\left(\delta_{i}\right)\end{array}$ & $\begin{array}{l}\text { Repair Rates } \\
\left(\mu_{i}\right)\end{array}$ & $\begin{array}{l}\text { Av. } \\
\text { (Max.) } \%\end{array}$ \\
\hline 1. & $\delta_{1}=\delta_{2}=0.001$ & $\mu_{1}=\mu_{2}=0.4$ & 86.52 \\
\hline 2. & $\delta_{3}=\delta_{4}=0.005$ & $\mu_{3}=\mu_{4}=0.4$ & 88.82 \\
\hline 3. & $\delta_{5}=0.005$ & $\mu_{5}=0.4$ & 87.94 \\
\hline 4 & $\delta_{6}=0.001$ & $\mu_{6}=0.4$ & 86.59 \\
\hline
\end{tabular}

\section{References}

1. N. Arora, D. Kumar, International Journal Management and Systems, 16, 2,(2000) 137-156.

2. E. Balaguruswamy, Reliability Engineering, (Tata McGraw Hill, New Delhi 1984).

3. S.Kumar, P.C. Tewari, International Journal of Industrial Engineering Computations, 2, 2011, 689-698. 